
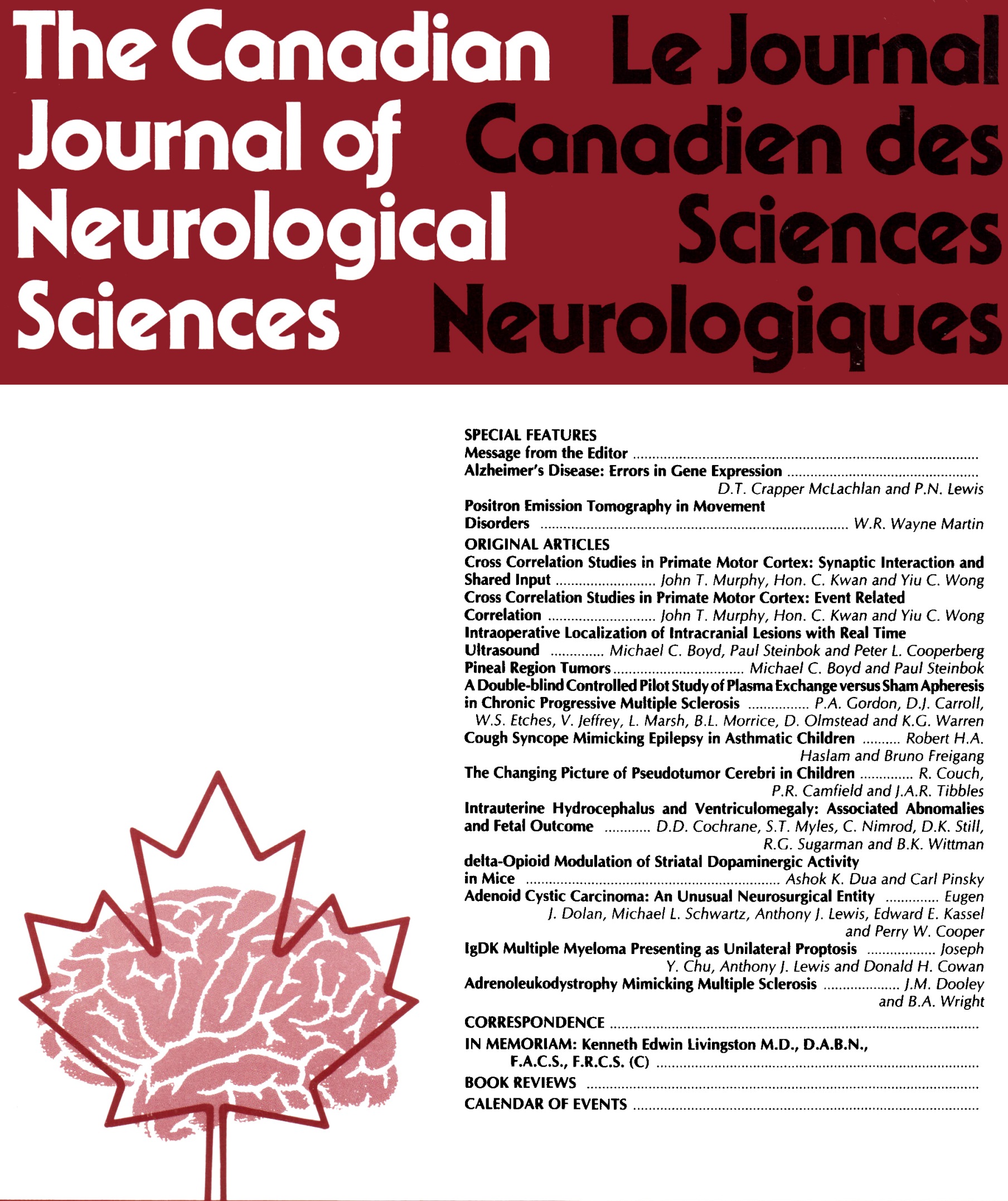

\title{
SPECIAL FEATURES
}

Message from the Editor

Alzheimer's Disease: Errors in Gene Expression

Positron Emis

D.T. Crapper Mclachlan and P.N. Lewis

Disorders

W.R. Wayne Martin

\section{ORIGINAL ARTICLES}

Cross Correlation Studies in Primate Motor Cortex: Synaptic Interaction and Shared Input ...................... John T. Murphy, Hon. C. Kwan and Yiu C. Wong Cross Correlation Studies in Primate Motor Cortex: Event Related

Correlation ........................ John T. Murphy, Hon. C. Kwan and Yiu C. Wong Intraoperative Localization of Intracranial Lesions with Real Time

Ultrasound ............ Michael C. Boyd, Paul Steinbok and Peter L. Cooperberg Pineal Region Tumors ................................ Michael C. Boyd and Paul Steinbok A Double-blind Controlled Pilot Study of Plasma Exchange versus Sham Apheresis in Chronic Progressive Multiple Sclerosis .............. P.A. Gordon, D.J. Carroll,

W.S. Etches, V. Jeffrey, L. Marsh, B.L. Morrice, D. Olmstead and K.C. Warren Cough Syncope Mimicking Epilepsy in Asthmatic Children ......... Robert H.A. Haslam and Bruno Freigang

The Changing Picture of Pseudotumor Cerebri in Children ............ $R$. Couch, P.R. Camfield and I.A.R. Tibbles

Intrauterine Hydrocephalus and Ventriculomegaly: Associated Abnomalies and Fetal Outcome …....... D.D. Cochrane, S.T. Myles, C. Nimrod, D.K. Still, R.C. Sugarman and B.K. Wittman delta-Opioid Modulation of Striatal Dopaminergic Activity

in Mice ................................................... Ashok K. Dua and Carl Pinsky Adenoid Cystic Carcinoma: An Unusual Neurosurgical Entity ............. Eugen I. Dolan, Michael L. Schwartz, Anthony I. Lewis, Edward E. Kassel and Perry W. Cooper IgDK Multiple Myeloma Presenting as Unilateral Proptosis ................ Joseph Y. Chu, Anthony J. Lewis and Donald H. Cowan Adrenoleukodystrophy Mimicking Multiple Sclerosis ................. I.M. Dooley and B.A. Wright

CORRESPONDENCE

IN MEMORIAM: Kenneth Edwin Livingston M.D., D.A.B.N.,

F.A.C.S., F.R.C.S. (C)

BOOK REVIEWS

CALENDAR OF EVENTS

XX Canadian Congress of Neurological Sciences Montréal, Québec

June $25-28,1985$

\section{The Official Journal of}

The Canadian Neurological Society

The Canadian Neurosurgical Society

The Canadian Society of Clinical Neurophysiologists

The Canadian Association for Child Neurology 


\section{When patients show prominent dyskinesia \\ or wearing-off reactions on long-term levodopa}




\author{
Editor/Rédacteur en chef Robert G. Lee Calgary \\ Associate Editors/Rédacteurs associés André Barbeau Montreal \\ Harvey B. Sarnat Calgary \\ Founding Editor/Fondateur-rédacteur Robert T. Ross Winnipeg \\ Book Review Editor/Rédacteur de critiques de livres T. Peter Seland Calgary \\ Managing Editor/Adjoint administratif Sally A. Gregg Calgary
}

\title{
Editorial Board
}

Albert J. Aguayo Montreal

Henry J.M. Barnett London

Paul Bédard Quebec

Henry B. Dinsdale Kingston

Guy Geoffroy Montreal

Alan Hudson Toronto

Yves Lamarre Montreal

Bernard Lemieux Sherbrooke

William J. Logan Toronto

Morton Low Vancouver

Thomas P. Morley Toronto
Thomas ). Murray Halifax

Donald Paty Vancouver

Sidney J. Peerless London

Terry Picton Ottawa

Jean Reiher Sherbrooke

Leo P. Renaud Montreal

Barry Rewcastle Calgary

Matthew W. Spence Halifax

William G. Tatton Toronto

Bryce Weir Edmonton

\section{Publications Committee}

John Wherrett Toronto

Terry Myles Calgary
Andrew Eisen Vancouver John Tibbles Halifax

\section{The Official Journal of:}

\section{The Canadian Neurological Society}

President - Robert F. Nelson

Secretary-Treasurer - Garth M. Bray, 1650 Cedar Avenue, Montreal, Quebec

H3G 1A4

The Canadian Society of Clinical Neurophysiologists

President - Terence Picton

Secretary-Treasurer - R. Gordon Blair 25 Leonard Avenue

Suite 309

Toronto, Ontario

M5T 2R2

\author{
The Canadian Neurosurgical Society \\ President - Stanley Schatz \\ Secretary-Treasurer - Alain Godon, \\ 12361 Notre-Dame-des Anges St., \\ Montreal, Quebec \\ H4) $2 \mathrm{C} 3$
}

The Canadian Association for Child Neurology

President - Frederick Andermann

Secretary-Treasurer - Daune L. McGregor, Hospital for Sick Children 555 University Avenue Toronto, Ontario M5G $1 \times 8$

\footnotetext{
The Canadian Journal of Neurological Sciences is published quarterly by University of Calgary Press. The annual subscription rate is $\$ 40.00$ for Canada and the U.S.A. $\$ 44.00$ elsewhere. Internes, Residents Pre- and Post-Doctoral Students $\$ 20.00$ per annum. Single copies $\$ 12.00$ each. All communications and subscriptions should be sent to the Editor, Canadian Journal of Neurological Sciences, Room 1496, Faculty of Medicine, University of Calgary, 3330 Hospital Drive N.W., Calgary, Alberta, Canada T2N 4N1. Telephone: (403) 283-4072.

COPYRIGHT ${ }^{\circ} 1985$ by THE CANADIAN IOURNAL OF NEUROLOGICAL. SCIENCES INC. No part of this journal may be reproduced in any form without the prior permission of The Canadian Journal of Neurological Sciences. Mailed under second class registration number 3307 . Postage paid at Calgary, Alberta. This journal is indexed by Index Medicus, Excerpta Medica and Current Contents - Clinical Practice and Life Sciences.

Advertising representative/Représentant de publicité Lex Publications, 431 Alden Road, Markham, Ontario L3R 3L.4 - (416) 477-2030 Suite 390, 3333 Cavendish Blvd., Montreal, Quebec H4B 2M5 - (514) 487-4412/4

Printer/Imprimeur McAra Printing Limited, 105, 2507 - 12th Street N.E., Calgary, Alberta T2E 7L5

ISSN $0317 \cdot 1671$
} 


\section{Frequent problems of long-term levodopa therapy ${ }^{8}$}

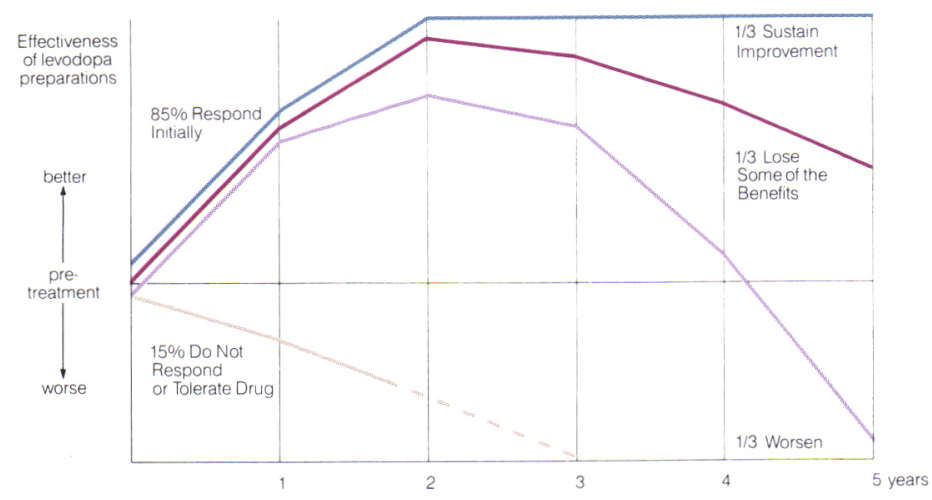

With time, the benefits of levodopa can decline, and patients may demonstrate prominent dyskinesia or signs of wearing-off such as:

$\square$ performance fluctuations

$\square$ early morning stiffness

$\square$ foot cramps

$\square$ end-of-dose deterioration

$\square$ on-off phenomenon

\section{Dopamine-like action ${ }^{3}$}

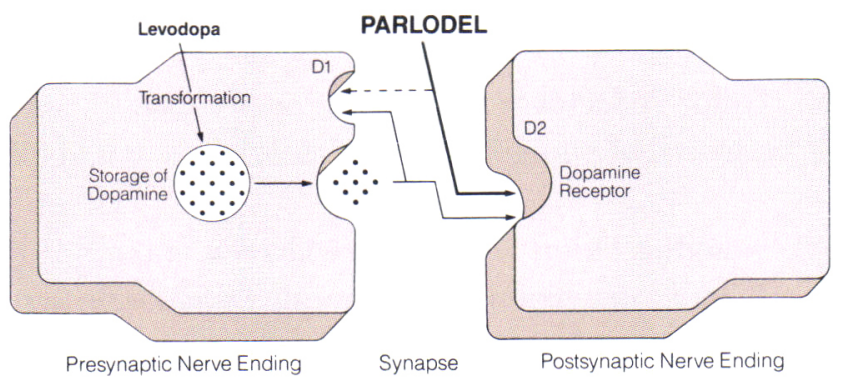

Help protect the quality of life for your Parkinson patients over the long term with Parlodel.2,4 Added to levodopa, it may allow lower doses for fewer longterm levodopa side effects ${ }^{4,5,6}$, and prolong the total useful period of active treatment. ${ }^{1}$

$\square$ Primary effect is directly on postsynaptic receptors. ${ }^{3}$

$\square$ Does not require transformation for its dopaminomimetic effect. ${ }^{3}$

$\square$ Combined therapy with levodopa often leads to significantly improved control. ${ }^{9}$

$\square$ May permit lower levodopa doses. ${ }^{4,5}$

$\square$ Longer plasma half-life (Parlodel 2-8 hours vs. levodopa 1 hour). ${ }^{9}$

$\square$ Mainly type D2 dopamine receptor agonist activity.

\section{"PARLODE[ \\ Can help prolong effective control ${ }^{1}$}




\section{Add Parlodel for improved quality of life $\mathrm{f}^{4,7}$}

In combination with levodopa, Parlodel may provide effective long-term control of Parkinson symptoms ${ }^{9}$, with decreased functional disability and increased mobility. ${ }^{2}$

\section{Mean improvement chart}

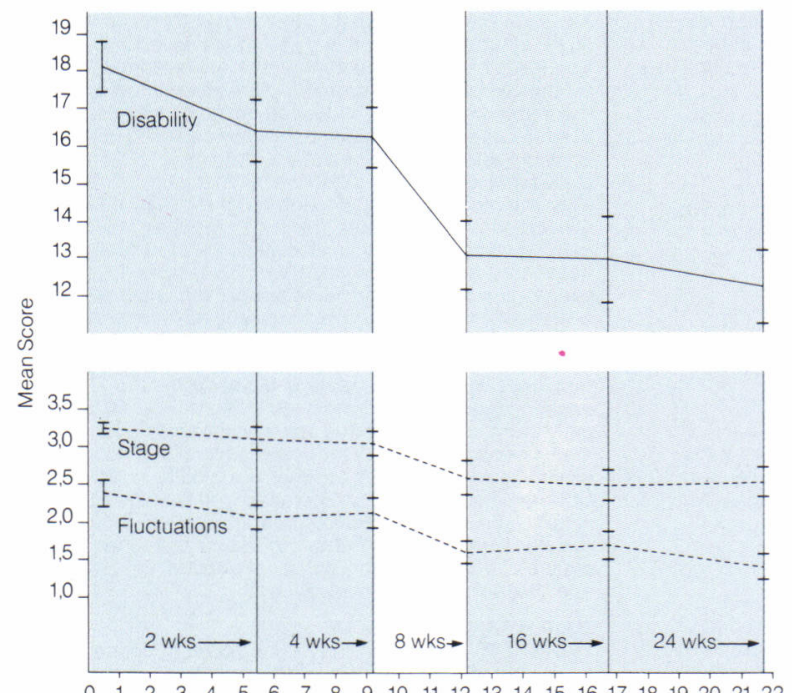

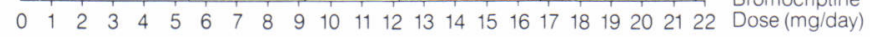
$n=33$

Mean improvements during adjunctive therapy with Parlodel. ${ }^{4}$
In a recently reported Canadian multicentre trial of Parlodel as adjunctive therapy ${ }^{4}$

$43 \%$ improvement in end-of-dose deterioration in a majority of patients

$\square 33 \%$ reduction in total disability scores

$\square$ low mean daily doses of Parlodel $12 \mathrm{mg}$ (8 weeks)

$22 \mathrm{mg}$ (24 weeks)

$\square 15 \%$ average decrease of levodopa

\section{Add Parlodel}

When levodopa no longer provides sufficient control, adding Parlodel is an alternative to increasing the dose of levodopa. Likewise, Parlodel can be an important adjunct when prominent dyskinesia appear. Parlodel - a new era in the treatment of Parkinson's disease.

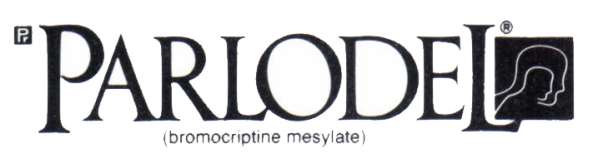

for added control 


\section{ADD \\ PARLODE[ \\ For added control}

ACTIONS Parlodel (bromocriptine mesylate) is a dopaminomimetic ergot derivate with $\mathrm{D}_{2}$ type dopamin receptor agonist activity, and has also $D$, dopamine receptor antagonist properties. The dopaminomimetic activity of bromocriptine in the striatum is considered responsible for the clinical benefits seen in selected patients with Parkinson's Disease, when low doses of the drug are gradually added to levodopa therapy in the drug are gradually added to levodopa therapy in patients on long-term treatment who develop late 列 medication. Excessive dopaminomimetic drive may however, provoke psychotic and other adverse reactions.

The extreme variability in G.l. tract absorption, and the extensive and individually variable first-pass metabolism is responsible for the broad variability in plasma concentrations of bromocriptine and, in part, for the variability in dose response.

INDICATIONS* Parkinson's Disease: Parlodel (bromocriptine mesylate) has been found to be clinically useful as an adjunct to levodopa (usually with a decarboxylase inhibitor), in the symptomatic management of selected patients with Parkinson's Disease who experience prominent dyskinesia or wearing off reactions on long-term levodopa therapy.

Patients on long-term treatment who are beginning to deteriorate on levodopa therapy may be controlled by reducing the dose of levodopa and adjusting the frequency and schedule of drug administration. Patien maintained on optimal dosages of levodopa who still experience prominent dyskinesia and/or end-of-dose failure, may benefit from the concomitant use of Parlodel, by decreasing the occurrence and/or severity of these manifestations. Since rapid escalation of bromocriptine doses causes severe adverse reactions,
it is recommended to combine a slow increase of Parlodel, usually with a concomitant, gradual and limited reduction of levodopa dosage. Continued efficacy of bromocriptine for more than two years has not been established and there is some evidence that its efficacy tends to wane. Evidence available indicates that there is no consistent benefit from bromocriptine in patients who have not responded previously to levodopa, and studies have shown significantly more adverse reactions in bromocriptine treated patients than in patients treated with levodopa. Parlodel is not recommended in the treatment of newly diagnosed patients or as the sole medication in Parkinson's Disease.

CONTRAINDICATIONS Other than sensitivity to ergot alkaloids, no absolute contraindications to treatment with Parlodel (bromocriptine mesylate) are known. For procedure during pregnancy see "Use in Pregnancy" procedure during preg
under Precautions.

WARNINGS Long-term treatment (6-36 months) with Parlodel in doses of 20 to $100 \mathrm{mg} /$ day has been associated with pulmonary infilirates, pleural effusion associated with pulmonary infilirates, pleural effusion Parlodel was discontinued, these changes slowly reverted to normal.

PRECAUTIONS Parlodel (bromocriptine mesylate) may cause hypotension, primarily postural; periodic manitoring of the blood pressure, particularly during the first days of therapy, is advisable. In some patients dizziness (vertigo) may occur with Parlodel; patients should ness (vertigo) may occur with Parlodel; patients should therefore be cautioned against activities requiring rapid and precise responses such as driving an automobile has been determined.

Care should be exercised when administering Parlodel concomitantly with phenothiazines or antihypertensive agents. Due to drug interaction at the receptor site, dosage should be adjusted accordingly.

Alcohol should be avoided during treatment with Parlodel. In some patients, the concomitant use of Parlodel and alcohol has given rise to alcohol intoler ance and an increase in the severity and incidence of Parlodel's possible adverse reactions.

Parlodel should always be taken with food. In cases where severe adverse effects, such as nausea, vomiting, vertigo or headaches are severe or persisting, the therapeutic dosage of Partodel should be reduced to one-half tablet daily (1.25 mg) and increased gradually to that recommended.

As with all medication, Parlodel should be kept safely out of the reach of children.

Use in Pregnancy If the patient wishes to become pregnant, Parlodel (bromocriptine mesylate) should be stopped as soon as possible after conception is suspected. In this event immunological confirmation should be done immediately. When pregnancy is confirmed, Parlodel, like all other drugs, should be discontinued unless, in the opinion of the treating physician, the possible benefit to the patient outweighs the potential risk to the fetus.
In human studies with Parlodel (reviewed by Turkalj, I.), there were 1410 reported pregnancies, which yielded 1236 live and 5 stillborn infants from women who took Parlodel (bromocriptine mesylate) during early pregnancy. Among the 1241 infants, 43 cases ( 31 minor and 12 major) of congenital anomalies were reported. The inc dence $(3.46 \%)$ and type of congenital malformations and the incidence of spontaneous abortions $(11.13 \%)$ in and the incidence of spontaneous abortions $(11.13 \%)$ in erally reported for such occurrences in the population at large.

Gynecological Supervision All women patients receiving Parlodel continuously for six months or more should have a gynecological examination before therapy, yearly if still menstruating, and six-monthly if menopausal. The examination should include cervical and, if possible, endometrial cytology. Post-menopausa Parlodel therapy at the discretion of the physican because estrogen induced uterine bleeding may mask the presence of pathological lesions.

A lifetime rat study revealed that some animals developed uterine tumors and endometrial carcinoma thought to be due to a state of induced estrogen dominance. However, clinical experience in women with a variety of hyperprolactinemic and other conditions treated with Parlodel for months or years, failed to demonstrate abnormal trends in hormonal levels or in endometrial cytology.

Normoprolactinemic women treated with Parlodel should be given the lowest effective dose necessary to relieve their symptoms, in order to avoid the possibility of suppression of prolactin below normal levels, with a consequent impairment of lutea: function.

Use in Parkinson's Disease: Use of Parlodel (bromocriptine mesylate), particularly in high doses, may be associated with mental confusion and mental disturbances. Since patients with Parkinson's Disease disturbances. Since patients with Parkinson's Diseas should be exercised when treating such patients with should be
Parlodel.

Parlodel. levodopa may cause visual or auditory hallucinations. These usually resolve with dosage reduction, but discontinuation of Parlodel may be required in some cases. Rarely, atter high doses, have hallucinations persisted for several weeks following discontinuation of Parlodel. Caution should be exercised when administering Caution should be exercised when administering infarction, particularly if they have a residual atrial infarction, particularly if they have
nodal or ventricular arrhythmia.

Symptomatic hypotension can occur and, therefore, caution should be exercised when administering Parlodel, particularly in patients receiving antihypertensive medication. Periodic evaluation of hepatic, hematopoietic, cardiovascular and renal function is recommended.

Orug Interactions: The concomitant use of erythromycin may increase bromocriptine plasma levels.

ADVERSE REACTIONS The most frequently ob served adverse reactions are nausea, vomiting, headache and gastrointestinal side effects such as abdominal pain, diarrhea and constipation. All these effects may be minimized or even prevented by giving small initial doses of bromocriptine and by taking it with food

Postural hypotension which can, on rare occasions, lead to fainting and "shock-like" syndromes have been reported in sensitive patients. This is most likely to occur during the first few days of Parlodel treatment.

When bromocriptine is added to levodopa therapy, the incidence of adverse reactions may increase. The most common newly appearing adverse reactions in combination therapy were: nausea, abnormal involuntary movements, hallucinations, confusion, "on-off" phenomenon, dizziness, drowsiness, faintness, fainting, vomiting, asthenia, abdominal discomfort, visual disturbance, ataxia, insomnia, depression, hypotension, shortness of breath, constipation and vertigo.

Less common adverse reactions include, anorexia anxiety, blepharospasm, dry mouth, dysphagia, edema of the feet and ankles, erythromelalgia, epileptiform seizures, fatigue, headache, lethargia, mottling of skin nasal stuffiness, nervousness, nightmares, parethesia, skin rash, urinary frequency, urinary incontinence, urinary retention and rarely signs of symptoms of ergotism nary retention and rarely signs of symptoms of ergotism cramps of feet and legs or exacerbation of Raynaud's cramps of

syndrome. of blood urea nitrogen, SGOT, SGPT, GGPT, CPK, alkaline phosphatase and uric acid, which are usually transient and not of clinical significance.
The occurrence of adverse reactions may be lessened by temporarily reducing dosage to one-half tablet two or three times daily.

\section{SYMPTOMS AND TREATMENT OF OVERDOSE}

There have been several reports of acute overdosage with Parlodel (bromocriptine mesylate) in children an Symptoms reported included nausea, vomiting, dizzness, drowsiness, hypotension, sweating and hallucinations. Management is largely symptomatic; the cardiovascular system should be monitored. Metoclopramide can be used to antagonize the emesis and hallucinations in patients who have taken high doses.

\section{DOSAGE AND ADMINISTRATION Parlodel}

(bromocriptine mesylate) should always be taken with food.

Although Parlodel (bromocriptine mesylate) has been ound clinically useful in decreasing the severity and frequency of "on-off" fluctuations of late levodopa therapy, the decision to use bromocriptine as adjunctive treatment and the selection of dosage must be individualized in each case. A low dose is recommended. The initia! dose of Parlodel is one half of a $2.5 \mathrm{mg}$ tablet $(1.25 \mathrm{mg})$ at bedtime with food to establish initial tolerance. Thereafter, the recommended dosage is $2.5 \mathrm{mg}$ daily in two divided doses, with meals, (hali a $2.5 \mathrm{mg}$ tablet twice daily). The dosage may be increased very gradually, if necessary, by adding an additional $2.5 \mathrm{mg}$ per day, once necessary, by adding an additional $2.5 \mathrm{mg}$ per day, once
every 2 to 4 weeks, to be taken always in divided doses with meals. Increments should usually never exceed $2.5 \mathrm{mg}$. Clinical assessments are recommended at two week intervals or less during dosage titration, to ensure that the lowest effective dosage is not exceeded. The usual dosage range is from a few milligrams to $40 \mathrm{mg}$ daily in two or three divided doses with meals. The median dose varies with the experience of individual investigators, but can be around $10 \mathrm{mg}$ daily or higher During initial titration it is recommended that the dosage of levodopa should be maintained, if possible. Subsequently, it might be desirable to combine a slow increase of bromocriptine with a concomitant, limited and gradual reduction of levodopa.

\section{AVAILABILITY}

1. TABLETS each containing $2.5 \mathrm{mg}$ bromocriptine, as mesylate, available in bottles of 100 .

Scored $7 \mathrm{~mm}$, round compressed white tablets with "XC" on one side and "PARLODEL" on the reverse

2. CAPSULES each containing $5 \mathrm{mg}$ bromocriptine, as mesylate, available in bottles of 100. Caramel and white size 3 hard shell capsules with "PARLODEL" on one side and " $5 \mathrm{mg}$ " on the other.

\section{REFERENCES}

1. Levodopa: Long-term impact on Parkinson's disease. (editorial) Br. Med. J. 1981; 282:417-418

2. Lieberman A.N. ot al. Can. J. Neurol. Sci. 1984; 11(1): (Suppl.): 233-237.

3. Calne D.B. et al. Can. J. Neurol. Sci. 1984; 11(1): (Suppl.): 221-224.

4. Grimes J.D. et al Can J. Neurol. Sci. 1984; (4): 452.456 5. Grimes J.D. Can. J. Neurol. Sci. 1984; 11(1): 225-228.

6. Rascol A. et al. Can. J. Neurol. Sci. 1984; 11(1): 229-231.

7. Ludin H.P. et al. Lancet 1978; 2: 578-579.

8. Ludin H.P. $\theta$ t al. Lancet $1978 ;$. L $578-579$.

345-349.

9. Godwin-Austen R.B. Res. Clin. Forums 1981; 3(2): 19-23.

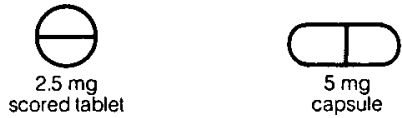

\section{PAAB
CCPP}

For information on other approved indications, please consult the Parlodel product monograph, available to physicians and pharmacists on request.

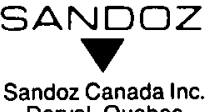

Dorval, Quebec H9R 4P5 


\section{Information for Authors}

The Canadian Journal of Neurological Sciences publishes orignal articles in the clinical and basic neurosciences. Manuscripts are considered for publication with the understanding that, except for identified review articles, they have not been published elsewhere except in abstract form and are not under simultaneous consideration by another publication. Manuscripts should be submitted to:

The Editor

Canadian Journal of Neurological Sciences

Faculty of Medicine,

University of Calgary

3330 Hospital Drive N.W.

Calgary, Alberta T2N 4N1

Manuscripts and all illustrations should be submitted in triplicate. Papers will be accepted in English or French. All papers should be accompanied by an abstract or a résumé of approximately 150 words on a separate page, preferably in both languages, although the Journal will provide the translation if requested. All manuscripts should be double spaced throughout, including references and legends for illustrations. Margins of at least $25 \mathrm{~mm}$ should be left on all sides.

For detailed instructions regarding style and layout, authors should refer to "Uniform requirements for manuscripts submitted to biomedical journals". Copies of this document may be obtained by writing to the Journal office, but the main points will be summarized here. Articles should be subdivided under conventional headings of "introduction", "methods and materials", "results" and "discussion" but other headings and subheadings will be considered if more suitable for a particular manuscript. A title page should identify the title of the article, authors, name of institution(s) from which the work originated, and the address and telephone number of the author to whom communications should be addressed. Pages of text should be numbered consecutively. Acknowledgements, including recognition of financial support, should be typed on a separate page at the end of the text.

References are to be numbered in the order of citation in the text. Those cited only in tables or in legends for illustrations are numbered in accordance with a sequence established by the first identification in the text of the particular table or illustration. Titles of journals should be abbreviated according to the style used in Index Medicus. References should be complete including the names of the first three authors followed by "et al" if there are more than three authors, full title, year of publication, volume number, and inclusive pagination for journal articles. Book or chapter references should also include the place of publication and name of the publisher. Examples of correct forms of references follow:

\section{Journals}

Poirier LJ, Filion M, Larochelle L, et al. Physiopathology of experimental parkinsonism in the monkey. Can J Neurol Sci $1975 ; 2$ : 255-263

\section{Chapter in a book}

McGeer PL, McGeer EG. Amino acid neurotransmitters. In: Siegel GJ, Albers RW, Agranoff BW, Katzman R, eds. Basic Neurochemistry. Boston: Little, Brown and Co, 1981: 233-254

Illustrations should be high quality glossy black-and-white photographic prints, preferably $127 \times 173 \mathrm{~mm}\left(5 \times 7^{\prime \prime}\right)$. Original artwork and radiographs should not be submitted. The additional cost of colour illustration must be borne by the author; quotations are available upon request from the Journal office. All figures should be identified on the back with the author's name and figure number. Letters and arrows applied to the figures to identify particular findings should be professional appliques suitable for publication. Photomicrographs should include a calibration bar with the scale indicated on the figure in the legend. Legends for illustrations should be typed on a separate page from the illustrations themselves.

Tables should each be on a separate page and be identified with the title or heading. Particular care should be taken in the preparation of tables to ensure that the data are presented in the most clear and precise format. Each column should have a short or abbreviated heading. Place explanatory matter in footnotes, not in the heading. Do not submit tables as photographs.

The SI system (système international d'unités) should be used in reporting all laboratory data, even if originally reported in another system. Temperatures are reported in degrees Celsius. Other measurements should be reported in the metric system. English language text may use either British or American spelling, but should be consistent throughout.

Review articles on selected topics also are published by the Journal. These are usually invited, but unsolicited reviews will be considered. It is suggested that authors intending to submit reviews contact the Editor in advance.

Letters to the Editor are welcome. These should be limited to two double-spaced pages and may include one illustration and a maximum of four references. 


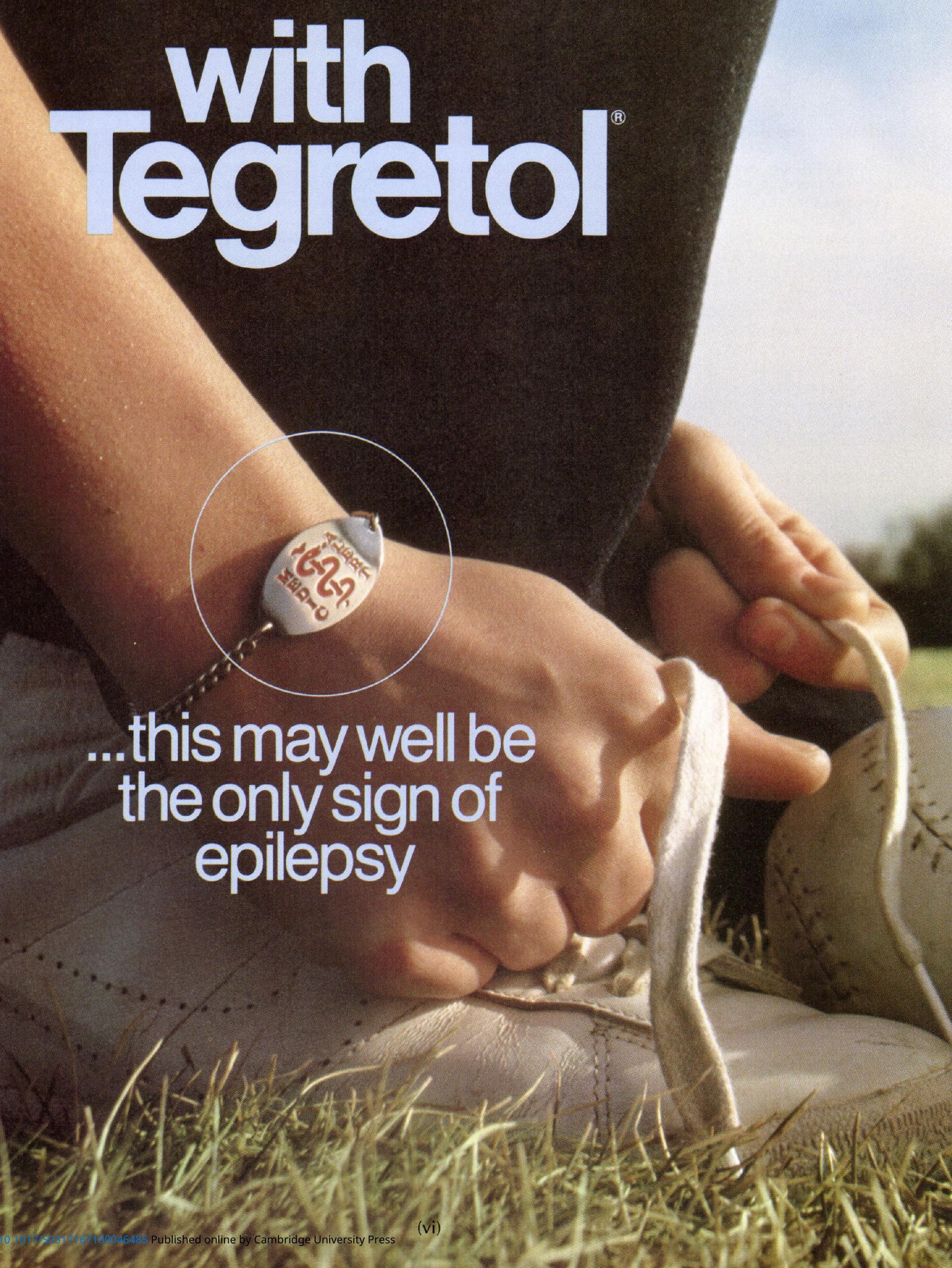


Tegretol ${ }^{\circledR}$ provides excellent seizure control without the penalty of excessive sedation; without hyperplasia of gingival mucosa, without hypertrichosis; and with minimal impairment of cognitive function. ${ }^{1,2,3}$

So give your epileptic patients a better chance at a more normal lifestyle. With Tegretol right at the start.

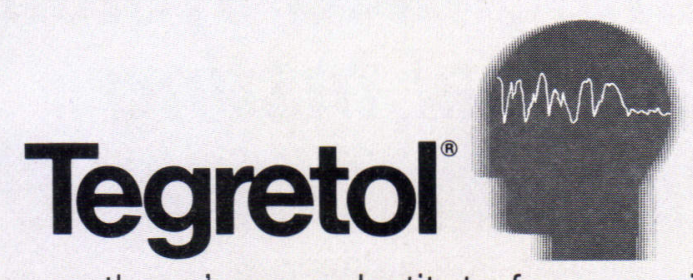

Because there's no substitute for experience.

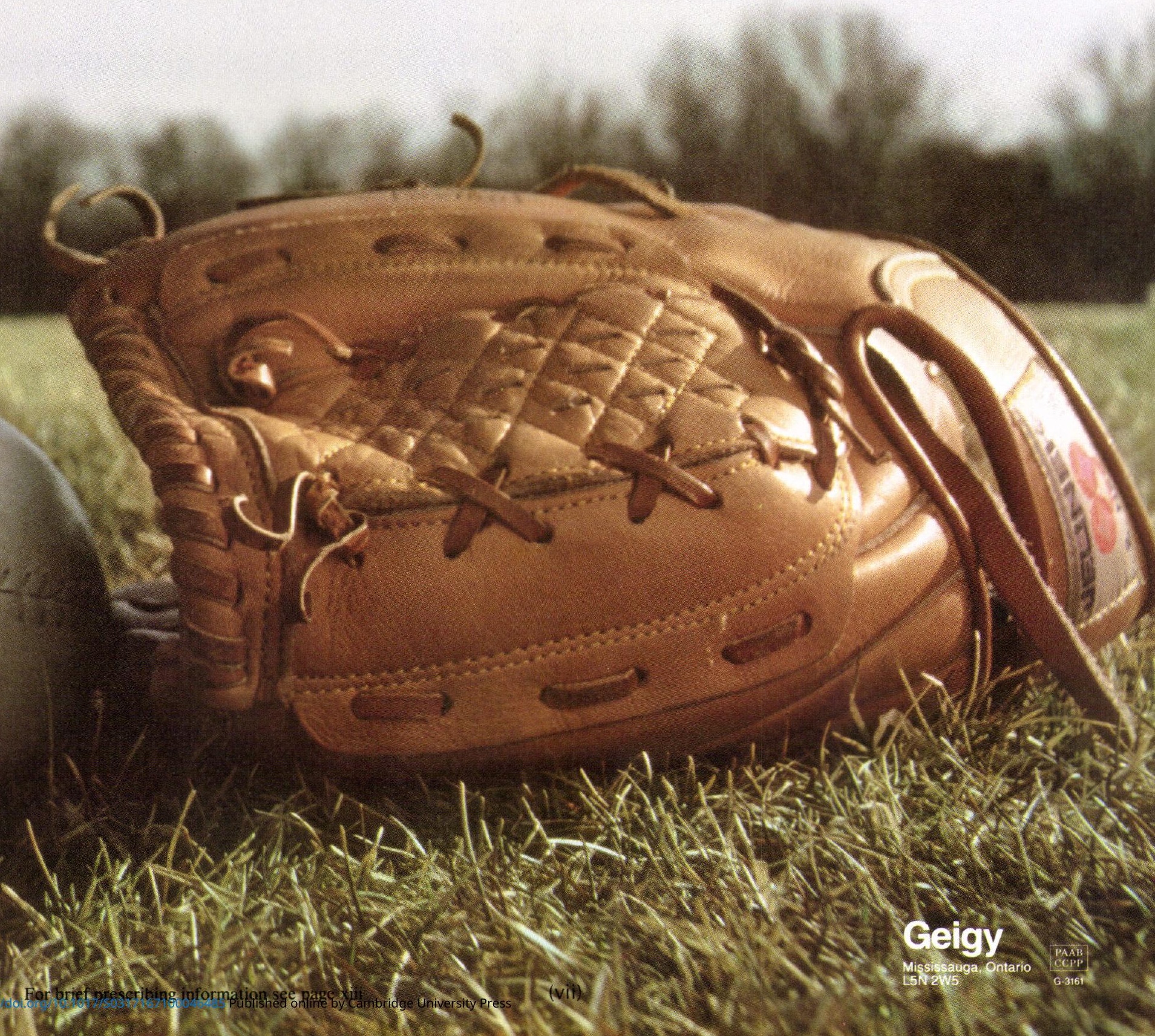




\section{D1 DANTEC Electromedical \& Scientific Equipment Ltd. 140 Shorting Road, Scarborough, Ontario, M1S 3S6, Canada \\ Phone: (416) 298-2091 - Telex: 065-25137}

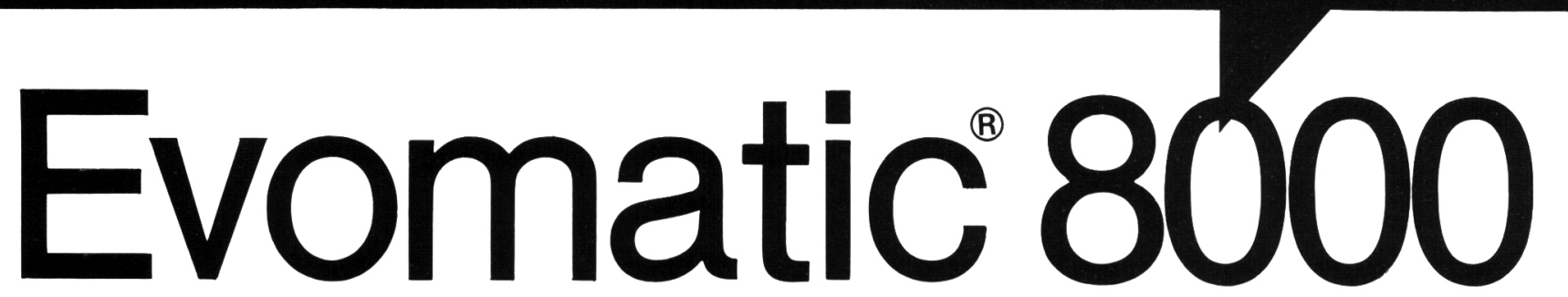

- completely integrated system for evoked potential testing

$\star$ Galvanically isolated patient unit

$\star$ One preamplifier for each electrode

$\star$ Fully computerized operation

$\star$ Powerful signal averaging and data processing

$\star 60$ user-defined programs stored on one disc

$\star$ Color display combined with finger-touch operation

$\star 1000$ points per channel with 12-bit resolution $\star$ Multi-functioning stimulators for auditory, visual and somatosensory evoked

$\star$ Storage of full patient journal including curves, patient data and text

$\star$ Eight color plotter printouts

$\star$ Built-in IEEE-488 interface

$\star$ Expandable from 1 to 8 channels

$\star$ Designed for ease of operation

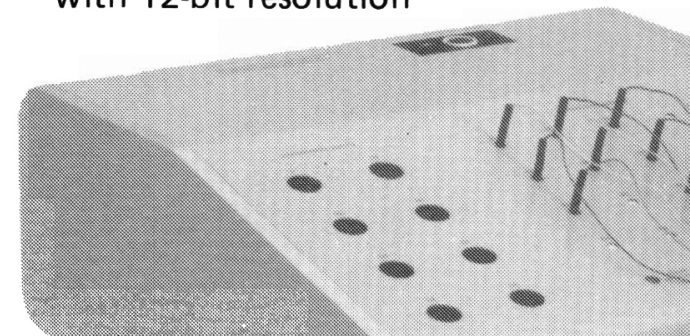




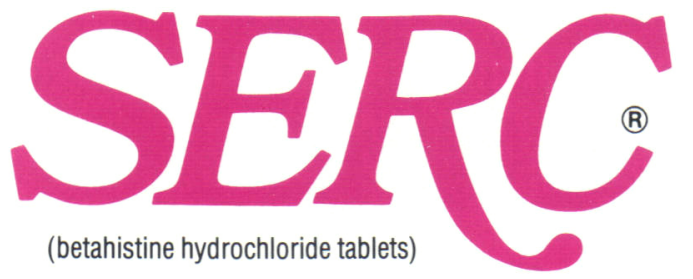

\section{For the}

\section{management of Vertigo}

\section{- Proven efficacy}

"(Serc) is now a proven, useful therapeutic agent in the treatment of Ménière's disease, especially in the control of vertigo."'

\section{Restores vestibular responses}

"In a preliminary trial (Wilmot 1971) using objective testing of both auditory and vestibular function... the results showed statistical significance in favour of Serc."2

\section{- Reduced severity of episodic vertigo} "... a significant improvement in favour of the drug (Serc) with regard to vertigo, tinnitus and deafness. Vertigo was the most responsive symptom."1

\section{Well tolerated}

\section{"No adverse reactions were observed."}

\section{REFERENCES:}

1 Frew, I.J.C. et al: Postgrad. Med. J.; 52:501-503, 1976.

2 Wilmot. T.J. et al: J. Laryng. Otol: 9:833-840, 1976

\section{PRESCRIBING INFORMATION:}

INDICATIONS: SERC may be of value in reducing the episodes of vertigo in Meniere's disease. No claim is made for the effectiveness of SERC in the symptomatic treatment of any form of vertigo other than that associated with Meniere's disease.

DOSAGE AND ADMINISTRATION: The usual adult dosage has been one to two tablets (4 mg. each) administered orally three times a day.

Recommended starting dose is two tablets three times daily. Therapy is then adjusted as needed to maintain patient response. The dosage has ranged from two tablets per day to eight tablets per day. No more than eight tablets are recommended to be taken in any one day.

SERC (betahistine hydrochloride) is not recommended for use in children. As with all drugs, SERC should be kept out of reach of children.

CONTRAINDICATIONS: Several patients with a history of peptic ulcer have experienced an exacerbation of symptoms while using SERC. Although no causual relation has been established SERC is contraindicated in the presence of peptic ulcer and in patients with a history of this condition. SERC is also contraindicated in patients with pheochromocytoma.

PRECAUTIONS: Although clinical intolerance to SERC by patients with bronchial asthma nas not been demonstrated, caution should be exercised if the drug is used in these patients USE IN PREGNANCY: The safety of SERC in pregnancy has not been established. Therefore, its use in pregnancy or lactation, or in women of childbearing age requires that its potential benefits be weighed against the possible risks.

ADVERSE REACTIONS: Occasional patients have experienced gastric upset, nausea and headache.

HOW SUPPLIED: Scored tablets of $4 \mathrm{mg}$ each in bottles of 100 tablets.

Full prescribing information available on request.

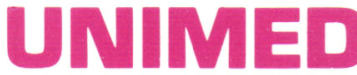

Dorval, Quebec H9P 2P4

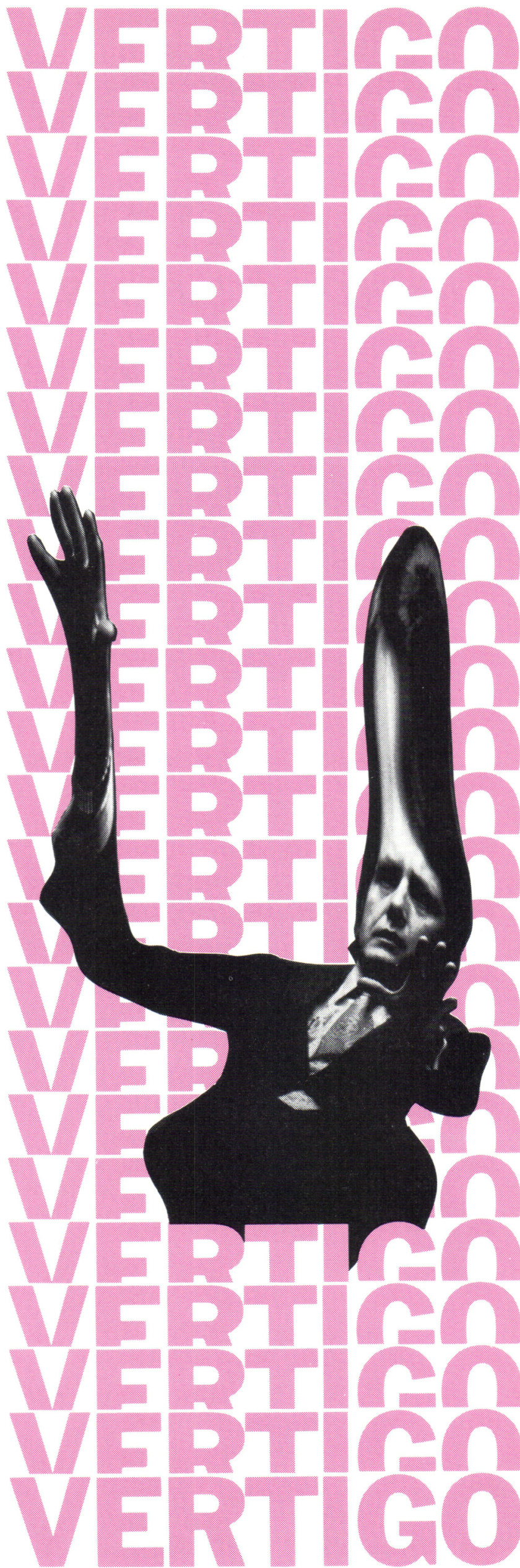




\section{DANTEC Electromedical \& Scientific Equipment Ltd.
140 Shorting Road, Scarborough, Ontario, M1S 3S6, Canada Phone: (416) 298-2091 - Telex: 065-25137}

\section{Neuromatic 2000 - a proven success}
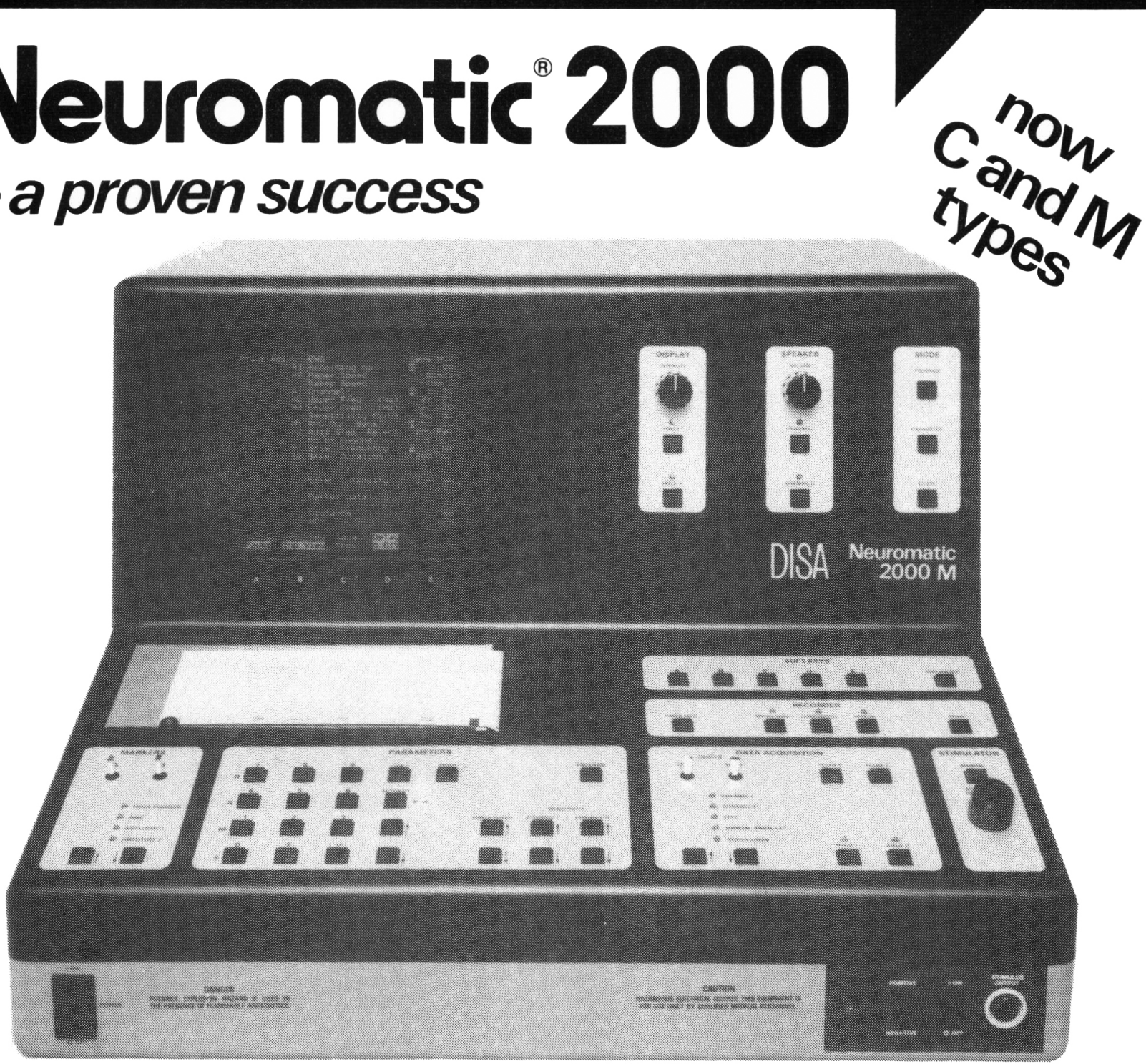

Neuromatic ${ }^{\circledR} 2000 \mathrm{C}$ - the Combined NeuroMyograph for Clinical Electromyography and Evoked Potentials

The Neuromatic ${ }^{\circledR} 2000 \mathrm{C}$ has powerful averagers with rejection facility, auditory stimulator with masking and visual stimulator with three square sizes.

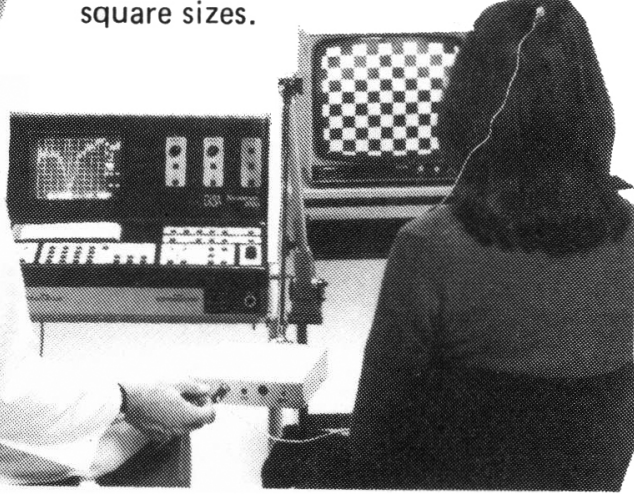

Neuromatic ${ }^{\circledR} 2000 \mathrm{M}$-the Myograph for Clinical Electromyography

The Neuromatic ${ }^{\circledR} 2000 \mathrm{M}$ has superior amplifiers and powerful averagers with rejection facility. Both the C-type and the M-type can be supplied with IEEE Interface for any standard computer.

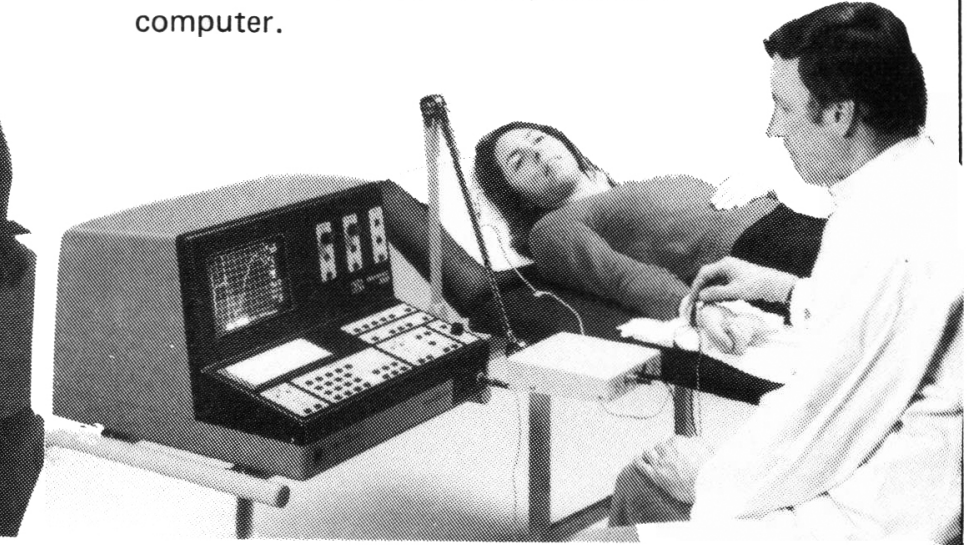




\section{Message from the Editor}

Citing references and preparing the bibliography is a common cause for tension headache in authors of scientific papers and their secretaries, or other individuals who type manuscripts. The situation is aggravated by the fact that the format for citing references varies considerably from one journal to another. If an author prepares a manuscript for a specific journal and then, for some reason, decides to submit it to another, a complete rewrite is often required.

In an attempt to overcome this difficulty the International Committee of Medical Journal Editors has prepared a set of guidelines entitled "Uniform requirements for manuscripts submitted to biomedical journals". Over 150 journals have now agreed to follow these requirements. After lengthy discussion, the editorial board of CJNS has decided to alter the format for quoting and listing references in our journal to conform to these uniform requirements. The major change is that references will now be cited numerically in the order in which they appear in the text and listed at the end of the paper in numerical sequence rather than alphabetical order.

This was by no means a unanimous decision by the editorial board, and arguments in favour of retaining our present format or using some alternative were presented in a most eloquent manner. It was pointed out that many readers like to know which authors are being quoted without having to constantly flip over to the reference list at the end of the paper. However, when 20 or more references are cited in the first paragraph of the introduction, as sometimes happens, the reader has to search amongst long lists of (Smith \& Jones 1965: Williams et al 1971; Filibuster \& Rogers 1982a, 1983) to determine exactly what the author is trying to say. Also, it should be noted that it is still possible with the new format to use the author's name in the text followed by the appropriate numeric citation if the writer feels that this is important.

It was also suggested that we change to a numerical system but list the references in alphabetical order in the bibliography. Presumably this would allow the reader to skim a reference list and see exactly who (perhaps himself) has been quoted. However, this argument is at least partialy invalidated by the fact that in at least $50 \%$ of papers the first author listed is not the senior author.

A summary of our new instructions for authors appears on page $v$ of this issue. A full copy of the document "Uniform requirements for manuscripts submitted to biomedical journals" can be obtained free of charge by writing to the editorial office. The full document also appears in the Canadian Medical Association Journal 1984; 131:1209-1213. Since there are many manuscripts presently "in the mill' which have been prepared according to the old instructions, it has been decided that 1985 will be a transition year. Until the end of December 1985, the Journal will receive manuscripts using either the old or new format, although authors who are starting new manuscripts are encouraged to follow the uniform requirements.

The task of reviewing manuscripts and selecting appropriate papers for publication is not an easy one. Most members of the editorial board contribute long hours to this process, but we also rely heavily on the opinions and comments of external reviewers. In many cases their suggestions for revisions result in substantial improvement in both the scientific and literary quality of a paper.

The names of our external reviewers for 1984 are listed below. On behalf of the editorial board, the authors, and the readers, I wish to express our appreciation.

Robert C. Lee Editor

$\begin{array}{llll}\text { Ashby P } & \text { Eisen A } & \text { Larbrisseau A } & \text { Ross RT } \\ \text { Becker LE } & \text { Ethier R } & \text { LeBlanc FE } & \text { Seshia SS } \\ \text { Blume WT } & \text { Fairholm D } & \text { Muller P } & \text { Sharpe JA } \\ \text { Brownell AKW } & \text { Feasby T } & \text { Myles ST } & \text { Sherwin AL } \\ \text { Bruni J } & \text { Friesen H } & \text { Nicolle LE } & \text { Sima AAF } \\ \text { Calne DB } & \text { Girvin J } & \text { Noseworthy JH } & \text { Smythe H } \\ \text { Camfield PR } & \text { Goodman G } & \text { Olivier A } & \text { Swanson H } \\ \text { Carpenter S } & \text { Haslam RHA } & \text { Payne D } & \text { Tasker RR } \\ \text { Cochrane DD } & \text { Hill A } & \text { Pryse-Phillips W } & \text { Tator C } \\ \text { Coupland SG } & \text { Humphrey JG } & \text { Rajput AH } & \text { Thomas H } \\ \text { Darwish HZ } & \text { Humphreys RP } & \text { Richardson PM } & \text { Tibbles JAR } \\ \text { Dolman L } & \text { Karpati G } & \text { Riopelle R } & \text { Vanasse M } \\ \text { Dunn H } & \text { Kileney P } & \text { Robertson DM } & \text { Verret SA } \\ \text { Ebers GC } & \text { Kirkham TH } & \text { Robertson W } & \text { Wherrett J } \\ \text { Edmeads JG } & & & \text { Wortzman G }\end{array}$


